\title{
CrystEngComm
}

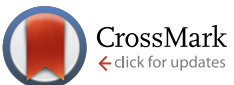

Cite this: CrystEngComm, 2016, 18 , 7330

\section{Control of the photochromic behavior of cobaloxime complexes with salicylidene-3- aminopyridine and 2-cyanoethyl groups by dual photoisomerization $\uparrow$}

\author{
Akiko Sekine, ${ }^{*}$ Sayaka Ina, Kohei Johmoto and Hidehiro Uekusa
}

\begin{abstract}
New dual photoisomeric cobaloxime complexes composed of salicylidene-3-aminopyridine derivatives and a 2-cyanoethyl group as axial ligands were synthesized. Photoisomerization of the 2-cyanoethyl group in the crystalline state was performed to control the photochromic properties of the salicylidene-3aminopyridine derivatives. The colors of the three cobaloxime crystals changed from pale yellow to orange or dark red when the crystals were irradiated with UV light. The red crystals returned to their original color when they were irradiated with visible light or kept in the dark. When the crystals were exposed to visible light before UV irradiation, the 2-cyanoethyl group bonded to the cobalt atom isomerized to the 1-cyanoethyl group with retention of the single crystal form. The crystals containing the 1-cyanoethyl group after photoirradiation also showed photochromism on exposure to UV light. However, the lifetime of the photochromic red species after 2-1 isomerization of the cyanoethyl group was significantly different from that before isomerization. The difference is well explained by the cavity volume around the central $\mathrm{C}-\mathrm{N}$ bond of the salicylidene moiety in the crystal of the red species.
\end{abstract}

\section{Received 29th April 2016, Accepted 10th June 2016 \\ DOI: 10.1039/c6ce01005a \\ www.rsc.org/crystengcomm}

cis-enol form. It has been proposed that these hydrogen bonds may stabilize the metastable trans-keto form and the longest lifetime would be realized for the crystal of $N-3,5$-ditert-butylsalicylidene-3-nitroaniline. $^{7}$

For $N$-3,5-di-tert-butylsalicylidene-3-carboxyaniline, in which the nitro group in $N$-3,5-di-tert-butylsalicylidene-3-nitroaniline is replaced by the carboxyl group, two polymorphic crystals can be obtained ( $\alpha$ and $\beta$ forms) and both show photochromism. The lifetimes of the red species of the $\alpha$ and $\beta$ forms are 17 and $780 \mathrm{~min}$, respectively, whereas the lifetime of $N$-3,5-di-tert-butyl-salicylidene-3-nitroaniline is $1200 \mathrm{~min}$. The crystal structures of the red species of the $\alpha$ and $\beta$ forms indicate that there is no intermolecular hydrogen bonding in the crystal structure of the red species of the $\alpha$ form, whereas there is one intermolecular hydrogen bond in the red species of the $\beta$ form. ${ }^{8}$ It is clear that the stability of the red species is closely related to the number of intermolecular hydrogen bonds in the crystal of the metastable red species.

To use SAs as photochromic materials, it is very important to control the time of the color change. Although the color

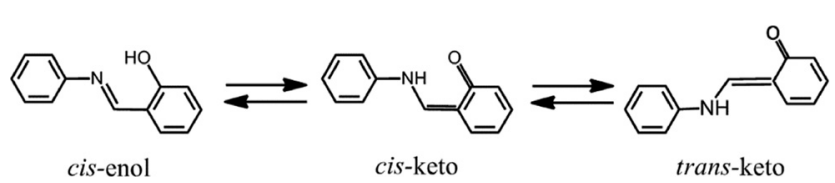

Scheme 1 Photochromic change of $N$-salicylideneaniline. 
change time is too fast to control on exposure to UV light, the color change (or fading) time of the red species strongly depends on the intermolecular interactions in the crystal. This suggests that if another photochangeable moiety can be substituted in photochromic SAs, different photochromic behaviors should be observed before and after photoreaction of the inserted moiety. It has been reported that the color of a cobalt complex with a diarylethene derivative ligand changes before and after a methanol molecule coordinates to the cobalt atom under methanol vapor. ${ }^{9}$

Cobaloxime complexes with a photochangeable alkyl group and a base ligand as axial ligands seem to be good candidates to control the photochromic behavior, because they show almost $100 \%$ photoisomerization on exposure to visible light without destroying the single crystal form. ${ }^{10-13}$ If such a cobaloxime moiety is introduced into a crystal containing SAs, it is expected that the lifetime of the red species of the SA would change before and after the photoisomerization of the alkyl group of the cobaloxime moiety.

In previous studies, ${ }^{14-16}$ cobaloxime complexes with a 3-cyanopropyl group and photochromic azobenzene derivatives as an axial alkyl group and base ligands, respectively, were prepared and the photochromic behavior of the azobenzene moiety was compared before and after photoisomerization from the 3-cyanopropyl group to the 1-cyanopropyl group. The rate of the color change because of trans-cis isomerization of azobenzene significantly changed. However, it was difficult to investigate how the structural change because of 3-1 photoisomerization influenced the rate of the color change because the crystal gradually decomposed in the process of trans-cis isomerization of the azobenzene moiety.

Cobaloxime complexes containing $\mathrm{N}$-salicylidene-3-aminopyridines (SAPs), in which the aniline moiety of SAs is replaced by 3-aminopyridine to coordinate to the cobalt atom, have been prepared to control the photochromism of SAP moieties. ${ }^{17}$ It was observed that the color fading rates of the SAP moieties significantly changed before and after the 3-cyanopropyl group was isomerized to the 1-cyanopropyl group with retention of the single crystal form on exposure to visible light.

In the present work, the 3-cyanopropyl group is replaced by the 2-cyanoethyl group to determine the effect of a smaller structural change. Five cobaloxime complex crystals with a 2-cyanoethyl group and different axial SAP ligands were prepared: $N$-3,5-di-tert-butylsalicylidene-3-aminopyridine (I), $N$-3,5-di-tertbutylsalicylidene-4-aminopyridine (II), $N$-5-methoxysalicylidene3-aminopyridine (III), $N$-5-chlorosalicylidene-3-amino-pyridine (IV), and $N$-5-bromosalicylidene-3-aminopyridine (V) (Fig. 1). Because photochromism on exposure to UV light was observed for I-III but not for IV and V, the crystal structures of I-V were analyzed to determine the reason why the latter two crystals showed no photochromism. Moreover, modified photochromic behavior was observed in I-III before and after photoisomerization of the 2-cyanoethyl group. The crystal structures of I-III before and after photoisomerization were

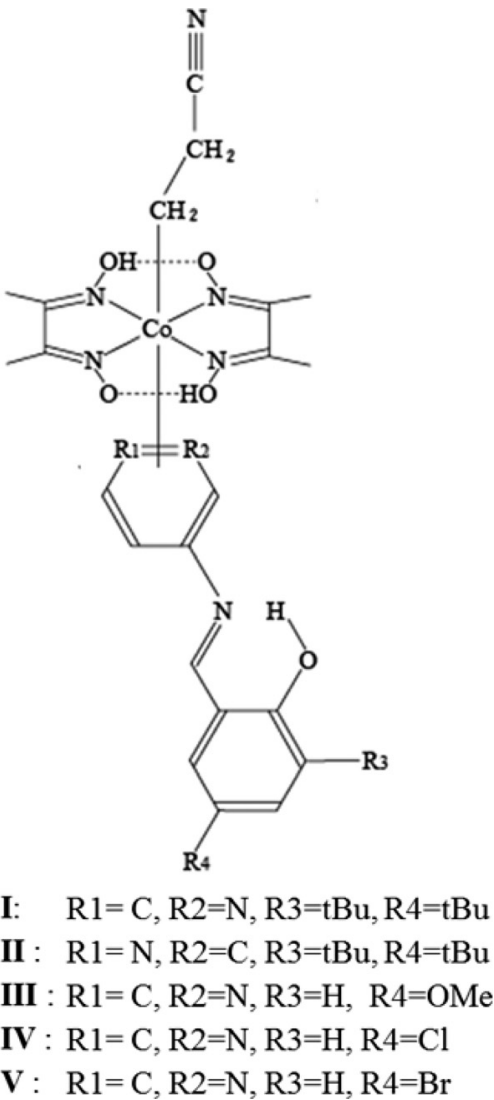

Fig. 1 Five (2-cyanoethyl)cobaloxime complexes with different axial ligands: I: N-3,5-di-tert-butyl-salicylidene-3-aminopyridine, II: N-3,5-ditert-butylsalicylidene-4-aminopyridine, III: N-5-methoxysalicylidene-3aminopyridine, IV: N-5-chlorosalicylidene-3-aminopyridine, V: N-5bromosalicylidene- 3-aminopyridine.

analyzed. The different photochromic behavior is discussed considering the structural changes during 2-1 photoisomerization.

\section{Experimental}

\section{Preparation}

(2-Cyanoethyl)(pyridine)cobaloxime. Cobalt(II) chloride hexahydrate $(4.77 \mathrm{~g}, 20 \mathrm{mmol})$ and dimethylglyoxime (4.68 g) were dissolved in $400 \mathrm{~mL}$ of methanol and the solution was stirred for $30 \mathrm{~min}$. An aqueous solution of sodium hydroxide (1.64 $\mathrm{g}$ of $\mathrm{NaOH}$ in $50 \mathrm{~mL}$ of water), $1.6 \mathrm{~mL}$ of pyridine, and $2.6 \mathrm{~mL}$ of 3-bromopropionitrile were rapidly added to the solution. An aqueous solution of sodium boron hydride $(0.78 \mathrm{~g}$ of $\mathrm{NaBH}_{4}$ and $150 \mathrm{~mL}$ of water) was then slowly added and the solution was kept in the dark for $3 \mathrm{~h}$. The resulting orange solid was washed with water.

$\mathrm{N}$-(Salicylidene)-3-aminopyridine derivatives and $\mathrm{N}$-(salicylidene)4-aminopyridine. 3-Aminopyridine (0.94 g, $10 \mathrm{mmol})$ was completely melted in a heating mantle at $60^{\circ} \mathrm{C}$, and then an equimolar amount of 3,5-di-tert-butylsalicylaldehyde, 5-methoxysalicylaldehyde, 5-chlorosalicylaldehyde, or 5-bromosalicylaldehyde was added. The mixture was then heated and stirred for $2 \mathrm{~h}$ at $c a$. $100{ }^{\circ} \mathrm{C}$ in an oil bath. The produced oily compound was left 
at room temperature overnight. The clumpy crude product was purified by recrystallization from methanol solution at $50{ }^{\circ} \mathrm{C}$. Either $\mathrm{N}$-(3,5-di-tert-butylsalicylidene)-3-aminopyridine, $N$-5-methoxysalicylidene-3-amino-pyridine, $\quad N$-(5-chlorosalicylidene)-3-aminopyridine, or $N$-(5-bromosalicylidene)-3-aminopyridine was obtained. When equimolar amounts of 4-aminopyridine and 3,5-di-tert-butylsalicylaldehyde were used instead of 3-aminopyridine and 3,5-di-tert-butylsalicylaldehyde, $N$-(3,5-di-tert-butylsalicylidene)-4-aminopyridine was obtained.

Cobaloxime complexes with $N$-(salicylidene)-3-aminopyridine derivatives and $N$-(salicylidene)-4-aminopyridine as axial ligands. (2-Cyanoethyl)(pyridine)cobaloxime (2.18 g) was dissolved in $100 \mathrm{~mL}$ of methanol. Water $(9 \mathrm{~mL})$ and ion-exchange resin (4.7 g, Dowex $50 \mathrm{~W}$-X8, mesh 50-100, $\mathrm{H}^{+}$ form) were added and the solution was stirred for $24 \mathrm{~h}$ in the dark. After removal of the ion-exchange resin, $\mathrm{N}$-3,5-di-tertbutylsalicylidene-3-aminopyridine $(5 \mathrm{mmol})$ was added and the solution was stirred at room temperature for $2 \mathrm{~h}$. The crude product (2-cyanoethyl)( $N$-3,5-di-tert-butyl-salicylidene-3aminopyridine)cobaloxime was obtained. (2-Cyanoethyl)cobaloxime complexes with other salicylidene-3-aminopyridine derivatives and salicylidene-4-aminopyridine as the axial ligands were obtained using the same method. Each powdered sample was dissolved in methanol at $50{ }^{\circ} \mathrm{C}$ and kept in the dark. Single yellow or orange crystals of $\mathbf{I}-\mathbf{V}$ were obtained.

\section{Photochromism of I-V owing to UV light irradiation}

Each powdered sample of $\mathbf{I}-\mathbf{V}$, which was obtained by grinding the single crystals, was irradiated with UV light generated by an ultrahigh-pressure $\mathrm{Hg}$ lamp (SAN-EI UVF-352S) at room temperature and passed through a glass filter (HOYA UV-360) that allows wavelengths around $360 \mathrm{~nm}$ to pass through. The distance between the powdered sample and the lamp was 5 $\mathrm{cm}$. The color of I changed from yellow to orange-red, as shown in Fig. 2. The red species thermally faded when the samples were kept in the dark at room temperature or irradiated with visible light. To more quantitatively examine the color change, $7.0 \mathrm{mg}$ of the crystalline powder of each of I-V was mixed with $350 \mathrm{mg}$ of barium sulfate in a mortar. The $\mathrm{UV} / \mathrm{vis}$ spectra of the powdered samples were measured before and after UV irradiation using a JASCO V-560 spectrometer. The absorbance at $500 \mathrm{~nm}$ significantly increased because of UV irradiation. The change of the absorbance of $\mathbf{I}$ is shown in Fig. 3. Similar spectral changes were observed for II
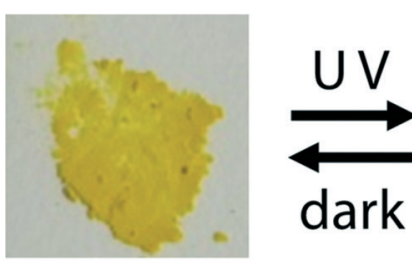

Yellow

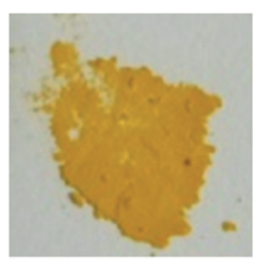

Orange-red
Fig. 2 Color change of I before and after UV irradiation.

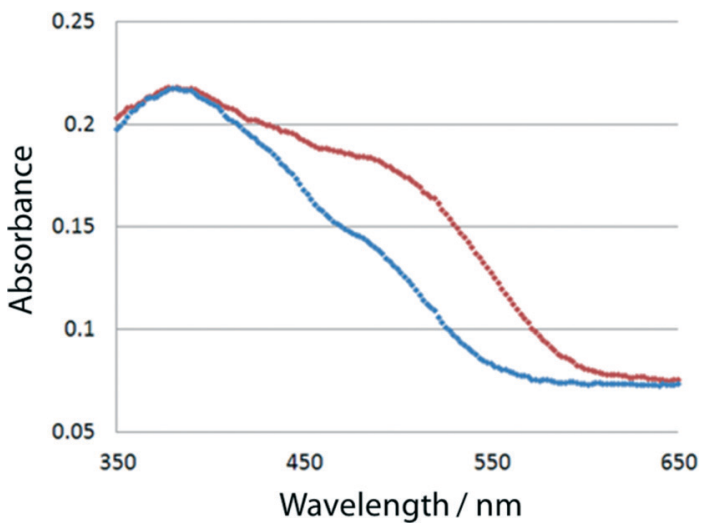

Fig. 3 Change in absorbance of I before (blue) and after $10 \mathrm{sec}$ (red) irradiation.

and III. However, no color changes were observed for IV and V. This suggests that the structural change from the cis-enol form to the trans-keto form (Scheme 1) occurred in the crystals of I, II, and III, but not in the crystals of IV and V.

\section{Isomerization on exposure to visible light}

$\mathrm{KBr}$ discs (conc. 1.2\%) made with powdered samples of I, II, and III, which were obtained by grinding the single crystals, were irradiated with visible light using a xenon lamp (SAN-EI, SUPERBRIGHT-152S), whose top was placed $5 \mathrm{~cm}$ from the disc. A glass filter (Toshiba Y44) was inserted between the disc and the lamp. The change in the $\mathrm{C} \equiv \mathrm{N}$ stretching vibration was measured at a constant interval with an infrared (IR) spectrometer (Bio-Rad Excalibur FTS 3000). With increasing irradiation time, the peak at $c a .2240 \mathrm{~cm}^{-1}$ owing to the 2-cyanoethyl group gradually decreased and a new peak owing to the 1-cyanoethyl group appeared at $c a .2200 \mathrm{~cm}^{-1}$ and then gradually increased. The IR spectra of I before and after 120 min irradiation are shown in Fig. 4. This indicates that the 2-cyanoethyl group changed to the 1-cyanoethyl group. The 21 isomerization rate exponentially changed in the early stage $(<3 \mathrm{~min})$, but the rate gradually decreased and the spectral changes were within the experimental error after $2 \mathrm{~h}$ exposure, as shown in Fig. 5.

For powdered samples of II and III, the changes in the IR spectra were measured in the same way. The isomerization rates in the early stage are somewhat different from that of $\mathbf{I}$. The changes became small after $2 \mathrm{~h}$ exposure. Although similar 2-1 isomerization was observed for IV and V, further quantitative measurements were not performed because they showed no photochromism with UV light irradiation.

\section{Photoisomerization of single crystals of I-III}

Single crystals of I, II, and III were irradiated with visible light from the xenon lamp through a filter (TOSHIBA, R620) at a distance of $2 \mathrm{~cm}$. This means that the crystal was irradiated with wavelengths longer than $620 \mathrm{~nm}$. 2-1 Isomerization proceeded with retention of the single crystal form. The changes of the cell dimensions of the single crystals of I, II, and III were within the experimental error after 85, 92.5, and 


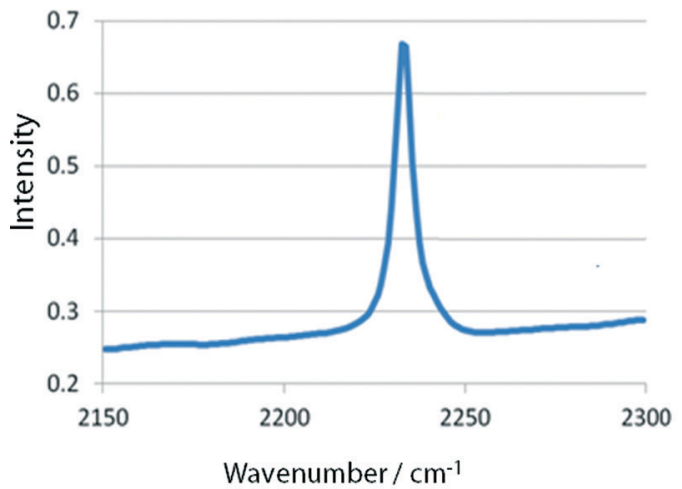

(a)

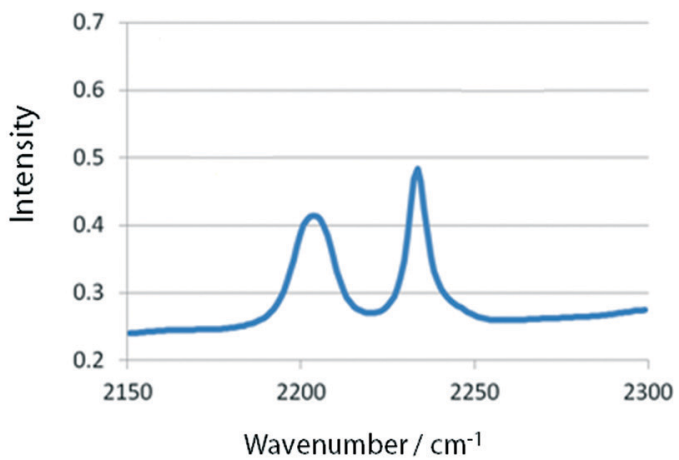

(b)

Fig. 4 Change in IR spectra of I (a) before and (b) after 120 min visible-light irradiation. The stretching vibration modes of the 2-ce and 1-ce groups appear at 2240 and $2200 \mathrm{~cm}^{-1}$, respectively.

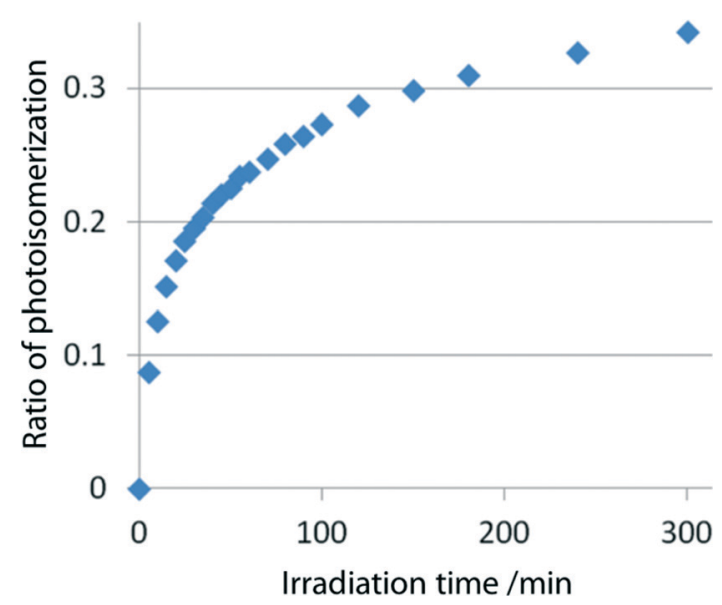

Fig. 5 Rate of the 2-1 photoisomerization of the 2-ce group of I at early stages on exposure to visible light.

$79 \mathrm{~h}$ exposure, respectively. Hereafter, these crystals are called I', II', and III', respectively.

\section{Thermal fading rates}

To measure the rate of thermal color fading, time-dependent UV/vis spectra were recorded for the red samples of I, II, and III at intervals of $5 \mathrm{~min}$ in the dark at room temperature. The fading rates after time $t(\mathrm{~min})$ were obtained from the ratio $\left(A_{t}-\right.$ $\left.A_{\infty}\right) /\left(A_{0}-A_{\infty}\right)$, where $A_{0}$ and $A_{t}$ are the integrated values of the absorbance from 400 to $700 \mathrm{~nm}$ at time 0 and time $t$, respectively, and $A_{\infty}$ is the corresponding integrated value before irradiation. The rate constant $k$ was determined assuming first-order kinetics using $-k t=\ln \left[\left(A_{t}-A_{\infty}\right) /\left(A_{0}-A_{\infty}\right)\right]$ before 21 isomerization (before Xe lamp exposure) and after 4 and 15 min irradiation with the lamp, as shown in Fig. 6. The lifetimes of the red species of I were obtained by $\tau=1 / k$.

For crystals of II and III, the lifetimes in the early stage are shown in Fig. 7(a) and (b), respectively. For powdered samples of I, II, and III, the lifetimes of the red species after 2-1 isomerization are shorter, longer, and shorter than the corresponding lifetimes before isomerization, respectively.

\section{Crystal structure analysis}

Crystals of I-V and I'-III' were mounted on a diffractometer (Rigaku, R-AXIS RAPID or XtalLab) and intensity data was collected with MoK $\alpha$ radiation $(\lambda=0.71073 \AA)$ at $173(2) \mathrm{K}$. The crystal data and experimental details for I-III and ' $\mathbf{I}^{\prime}-\mathbf{I I I}^{\prime}$ are shown in Table 1 . The corresponding data for $\mathbf{I V}$ and $\mathbf{V}$ are shown in Table 2. Semi-empirical absorption correction was applied. The crystal structures were solved with the program SHELXS97 (ref. 18) or SIR2011 (ref. 19) and refined with fullmatrix least-squares on $F^{2}$ with the program SHELXL2013. ${ }^{20}$ All of the non-hydrogen atoms, including disordered atoms, were refined with anisotropic temperature factors. Hydrogen atoms were obtained geometrically and refined assuming rigid motion with isotropic temperature factors. The non-hydrogen atoms of the minor part of the disordered tert-butyl group and the solvent methanol molecule in I were refined with isotropic temperature factors. The atoms of the photoproduced 1-cyanoethyl group of $\mathbf{I}^{\prime}$ were also refined with isotropic temperature factors. The 2-cyanoethyl and SAP groups of I, II, and II' are disordered. Refinement of the disordered atoms of the 2-cyanoethyl group and the minor part of the SAP group in II

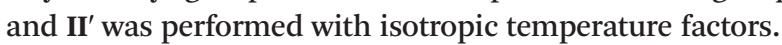

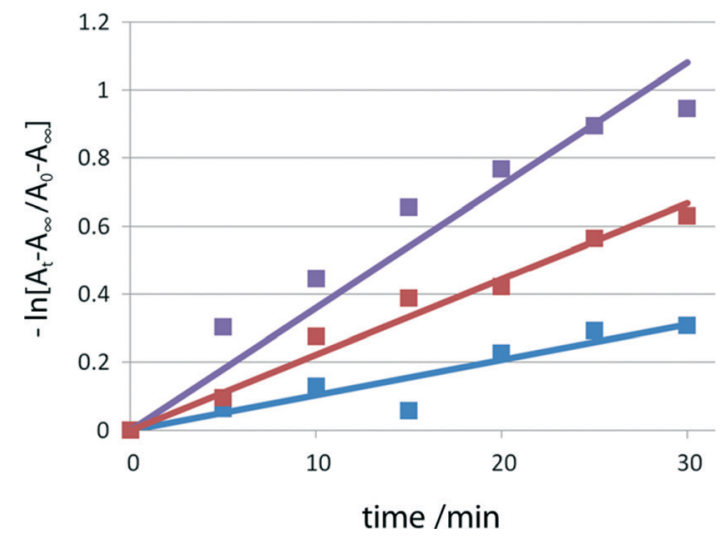

Fig. 6 Fading rates of I before visible-light irradiation (blue), and after $4 \mathrm{~min}$ (red) and $15 \mathrm{~min}$ (violet) irradiation. 


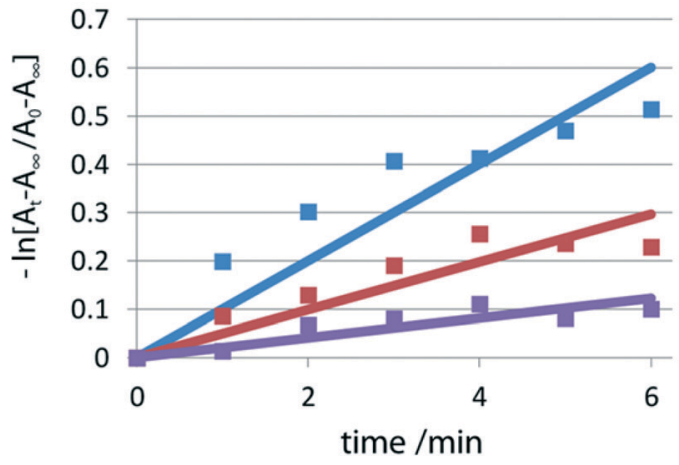

(a)

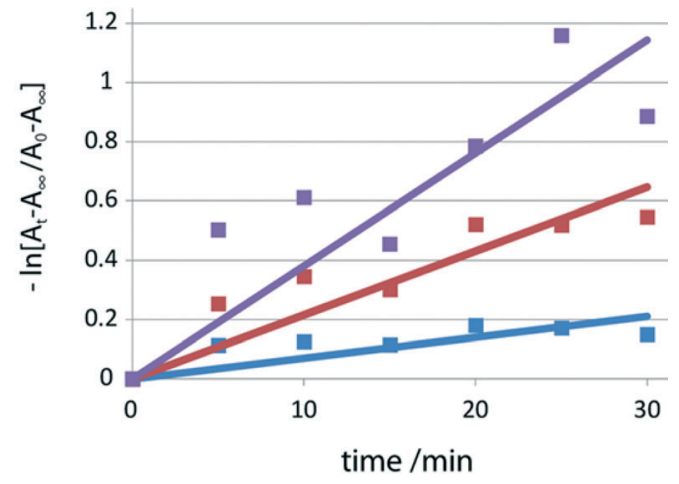

(b)

Fig. 7 Fading rates of (a) II and (b) III. The blue line is before irradiation. The red and violet lines are after 20 and 35 min irradiation in (a), and after 5 and 10 min irradiation in (b), respectively.

Table 1 Crystal data and the experimental details of I-III and I'-III'

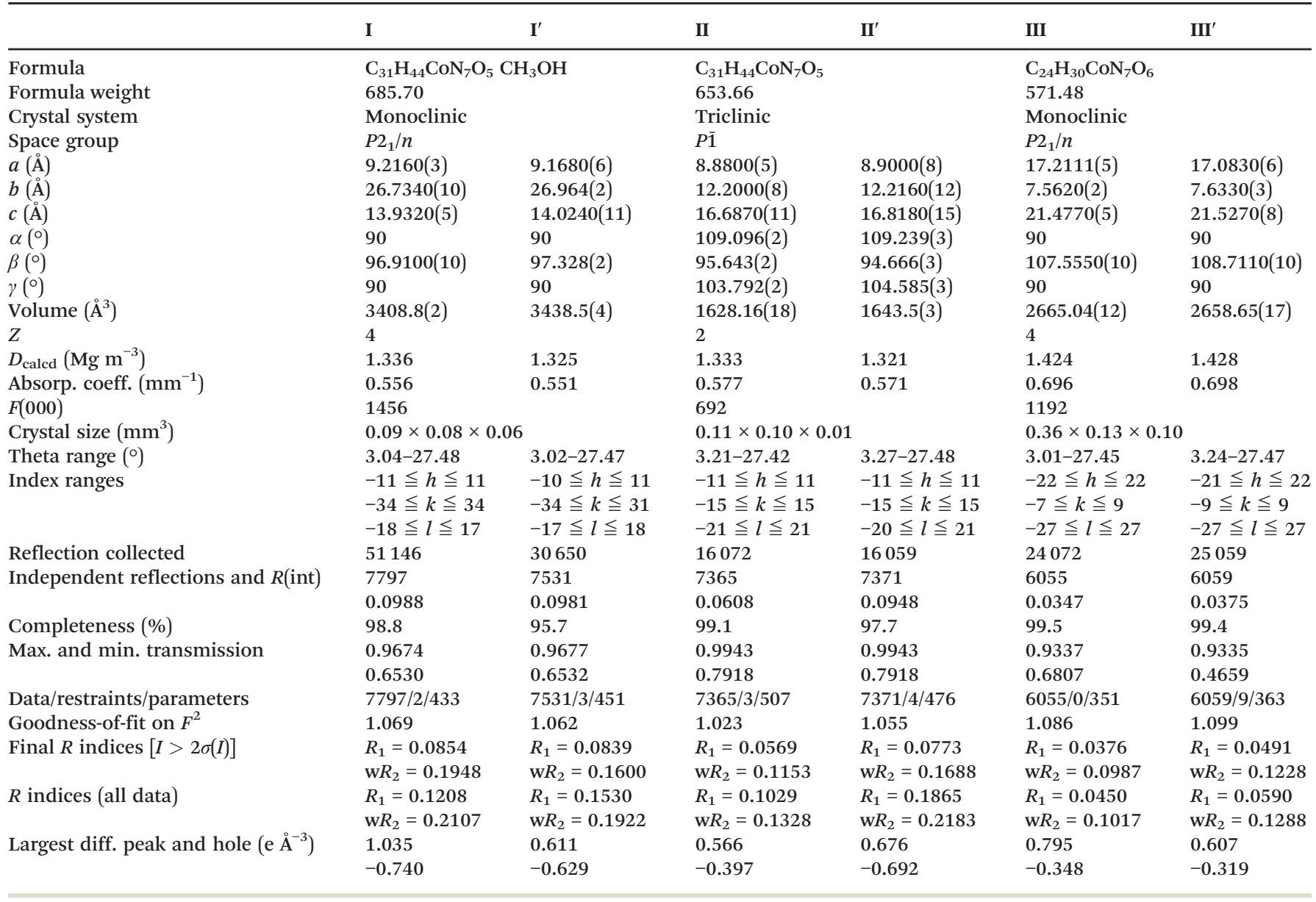

\section{Results and discussion}

\section{Crystal and molecular structures of $I$ and $I^{\prime}$}

The crystal structure of $\mathbf{I}$ viewed along the $a$ axis is shown in Fig. 8. There is a solvent methanol molecule in the crystal structure. The molecular structure is shown in Fig. 9(a). The 2-cyanoethyl group has a perpendicular conformation, which means that the conformation around the Co-C9-C10-C11 bond is trans. The $N$-salicylidene-3-aminopyridine moiety as a whole is nonplanar, but the salicylidene and 3-aminopyridine groups are planar and the dihedral angle between the two planes is $47.8(2)^{\circ}$. One of the two tert-butyl groups is disordered, and the occupancy ratio is $82: 18$.

The crystal structure of $I^{\prime}$ is essentially the same as that of I, although the unit cell volume is 29.7(2) $\AA^{3}$ larger. Several new peaks appear around the 2-cyanoethyl group in the 
Table 2 Crystal data and experimental details of IV and V

\begin{tabular}{|c|c|c|}
\hline & IV & $\mathbf{V}$ \\
\hline Formula & $\mathrm{C}_{23} \mathrm{H}_{27} \mathrm{ClCoN}_{7} \mathrm{O}_{5}$ & $\mathrm{C}_{23} \mathrm{H}_{27} \mathrm{BrCoN}_{7} \mathrm{O}_{5}$ \\
\hline Formula weight & 575.90 & 620.36 \\
\hline Crystal system & Monoclinic & Triclinic \\
\hline Space group & $P 2_{1}$ & $P \overline{1}$ \\
\hline$a(\AA)$ & $7.9620(7)$ & $8.4010(5)$ \\
\hline$b(\AA)$ & $8.4070(6)$ & $13.0930(9)$ \\
\hline$c(\AA)$ & $18.8990(14)$ & $13.7750(10)$ \\
\hline$\alpha\left(^{\circ}\right)$ & 90 & $63.746(2)$ \\
\hline$\beta\left({ }^{\circ}\right)$ & $94.566(2)$ & $89.633(2)$ \\
\hline$\gamma\left({ }^{\circ}\right)$ & 90 & $75.599(2)$ \\
\hline Volume $\left(\AA^{3}\right)$ & $126.02(17)$ & $1306.78(15)$ \\
\hline$Z$ & 2 & 2 \\
\hline Density calculated & 1.517 & 1.577 \\
\hline Absorption coeff. $\left(\mathrm{mm}^{-1}\right)$ & 0.836 & 2.233 \\
\hline$F(000)$ & 596 & 632 \\
\hline Crystal size $\left(\mathrm{mm}^{3}\right)$ & $0.13 \times 0.09 \times 0.04$ & $0.14 \times 0.09 \times 0.05$ \\
\hline Theta range $\left(^{\circ}\right)$ & $3.22-27.42$ & $3.18-27.42$ \\
\hline \multirow[t]{3}{*}{ Index ranges $\left({ }^{\circ}\right)$} & $-10 \leqq h \leqq 10$ & $-10 \leqq h \leqq 10$ \\
\hline & $-9 \leqq k \leqq 10$ & $-15 \leqq k \leqq 16$ \\
\hline & $-24 \leqq l \leqq 24$ & $-17 \leqq l \leqq 17$ \\
\hline Reflection collected & 12560 & 12892 \\
\hline Independent reflections and & 5130 & 5881 \\
\hline$R$ (int) & 0.1063 & 0.0740 \\
\hline Completeness (\%) & 99.7 & 99.1 \\
\hline \multirow[t]{2}{*}{ Max. and min. transmission } & 0.9673 & 0.8965 \\
\hline & 0.5285 & 0.4552 \\
\hline Data/restraints/parameters & $5130 / 1 / 334$ & $5881 / 0 / 331$ \\
\hline Goodness-of-fit on $F^{2}$ & 1.069 & 1.134 \\
\hline \multirow[t]{2}{*}{ Final $R$ indices $[I>2 \sigma(I)]$} & $R_{1}=0.0639$ & $R_{1}=0.0533$ \\
\hline & $\mathrm{w} R_{2}=0.1209$ & $\mathrm{w} R_{2}=0.1151$ \\
\hline \multirow[t]{2}{*}{ Final $R$ indices (all data) } & $R_{1}=0.1306$ & $R_{1}=0.1276$ \\
\hline & $\mathrm{w} R_{2}=0.1644$ & $\mathrm{w} R_{2}=0.1605$ \\
\hline Largest diff. peak and hole & 0.947 & 1.104 \\
\hline$\left(\mathrm{e} \AA^{-3}\right)$ & -0.919 & -1.261 \\
\hline Absolute structure parameter & $0.03(3)$ & - \\
\hline
\end{tabular}

difference electron density map of $\mathbf{I}^{\prime}$, which are assigned to atoms of the 1-cyanoethyl group. The ratio of the original

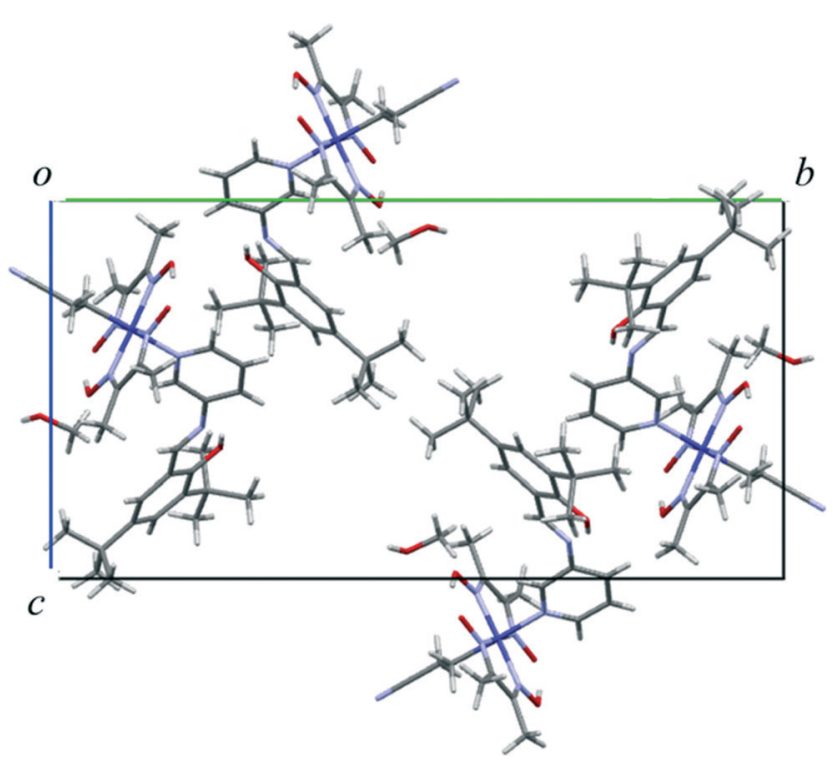

Fig. 8 Crystal structure of I viewed down the a-axis. The minor part of the disordered tert-butyl groups is omitted for clarity.

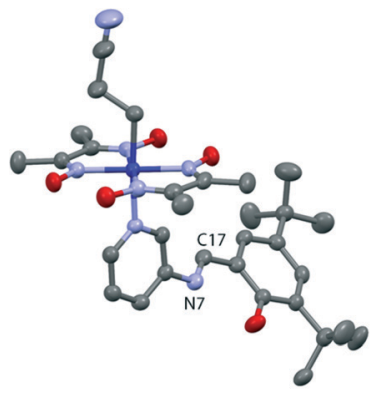

(a) (b)

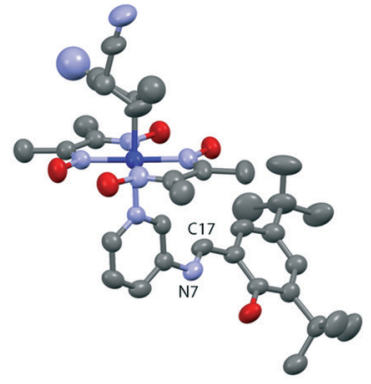

Fig. 9 Major parts of the molecular structures of I before (a) and after (b) visible-light irradiation. The produced 1-cyanoethyl and original 2-cyanoethyl groups take disordered structures in (b). Hydrogen atoms and solvent methanol molecule are omitted for clarity. The thermal ellipsoids of atoms are drawn at the $50 \%$ probability level.

2-cyanoethyl group to the produced 1-cyanoethyl group is 58 : 42. The configuration of the 1-cyanoethyl group is limited to $R$ or $S$ in an asymmetric unit, as shown in Fig. 9(b). The dihedral angle between the salicylidene moiety and the 3 -aminopyridine group is $45.8(3)^{\circ}$, which is similar to the original angle. The ratio of the disordered tert-butyl group changes to 71:29 and the occupancy factor of the solvent methanol molecule significantly decreases.

\section{Crystal and molecular structures of II and II'}

The 2-cyanoethyl and SAP groups in the crystal structure of II are disordered, as shown in Fig. 10(a). The 2-cyanoethyl group has a perpendicular conformation. The ratios of the major and minor components of the 2-cyanoethyl and SAP groups

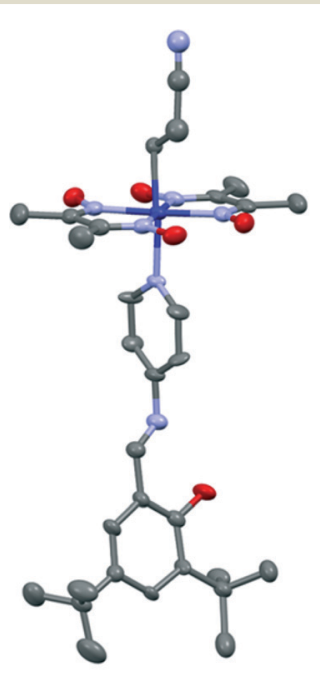

(a)

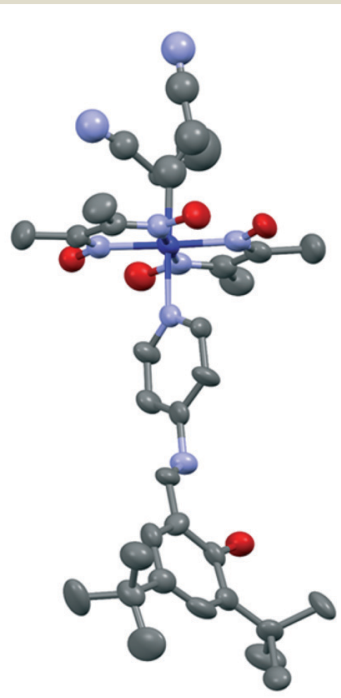

(b)
Fig. 10 Molecular structures of II before (a) and after (b) visible-light irradiation. Hydrogen atoms are omitted for clarity. The thermal ellipsoids of atoms are drawn at the $50 \%$ probability level. The minor parts of the disordered salicylideneaniline moiety and 2-cyanoethyl group in (a) and the salicylideneaniline moiety in (b) are omitted for clarity. 
are $61: 49$ and $69: 31$, respectively. Because the two groups are in close contact in the crystal structure, both groups may be disordered. The dihedral angles between the salicylidene and 3-aminopyridine groups are $88.6(5)^{\circ}$ and $77.1(11)^{\circ}$ for the major and minor parts of the SAP moiety, respectively.

The crystal structure of 'II' is essentially the same as that of

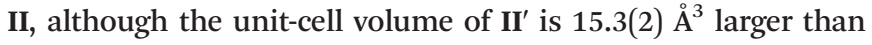
that of II. The 2-cyanoethyl group partly changes to the 1-cyanoethyl group. The molecular structure of $\mathbf{I I}^{\prime}$ is shown in Fig. 10(b). The ratio of the original 2-cyanoethyl group to the photoproduced 1-cyanoethyl group is $53: 47$. The configuration of the produced 1-cyanoethyl group is only $R$ or $S$ in an asymmetric unit. The SAP group is also disordered, and the ratio is $69: 31$, which is the same as that of II. The dihedral angles between the salicylidene and 3-aminopyridine groups are 85.3(7) $)^{\circ}$ and $71.3(14)^{\circ}$ for the major and minor parts, respectively, which are similar to the corresponding angles of II.

\section{Crystal and molecular structures of III and III'}

The 2-cyanoethyl and SAP groups in the crystal structure of III are ordered. The molecular structure of III is shown in Fig. 11(a). The 2-cyanoethyl group has a parallel conformation, which means that the conformation around the Co-C9C10-C11 bond is gauche. There is no short contact between the nitrogen atom of the 2-cyanoethyl group and the $\mathrm{N}-\mathrm{H}$ group of the salicylidene group. The $\mathrm{N}-\mathrm{H} \cdots \mathrm{N}$ distance is 3.746 or $3.887 \AA$, which is too long for a weak hydrogen bond. $^{21}$ The dihedral angle between the salicylidene and 3-aminopyridine groups is $32.50(9)^{\circ}$.

The crystal structure of 'III' is essentially the same as that of III, although the unit-cell volume of III' is 6.4(2) $\AA^{3}$ less than that of III. The 2-cyanoethyl group partly changes to the 1-cyanoethyl group. The molecular structure of 'III' is shown in Fig. 11(b). The occupancy factor of the original 2-cyanoethyl group became ca. 0.5. The photoproduced 1-cyanoethyl group takes a disordered structure with the $R$ and $S$ configurations with a ratio of $3: 2$ in an asymmetric unit. No intermolecular hydrogen bonds are formed for the $R$ and $S$ configurations. The dihedral angle between the

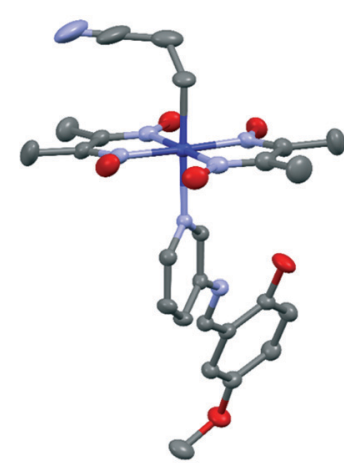

(a)

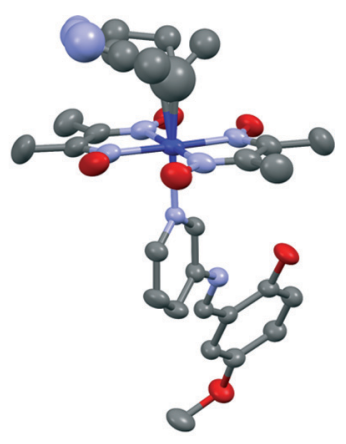

(b)
Fig. 11 Molecular structures of III before (a) and after (b) visible light irradiation. Hydrogen atoms are omitted for clarity. The thermal ellipsoids of atoms are drawn at the $50 \%$ probability level. salicylidene and 3-aminopyridine groups is $35.90(12)^{\circ}$, which is almost the same as the corresponding angle of III.

\section{Color fading rates before and after $2-1$ isomerization}

As shown in Fig. 5 and 6(a) and (b), the lifetimes before and after 2-1 photoisomerization are significantly different, and they are summarized in Table 3. For example, for the powdered sample of I, the lifetime of the colored species before 2-1 isomerization is $96 \mathrm{~min}$, but the lifetime gradually decreases on exposure to visible light and the lifetime is $28 \mathrm{~min}$ after irradiation with visible light for $15 \mathrm{~min}$. This clearly indicates that the structural change from the 2-cyanoethyl group to the 1-cyanoethyl group decreases the lifetime of the colored species of the SAP molecule coordinated to the cobalt atom from the opposite side of the cobaloxime plane.

For the powdered sample of II, the lifetime of the colored species before $2-1$ isomerization is $10 \mathrm{~min}$, but it increases to $49 \mathrm{~min}$ after the sample was irradiated with visible light for $35 \mathrm{~min}$. The lifetime of the colored species of III gradually decrease from $143 \mathrm{~min}$ before $2-1$ isomerization to $26 \mathrm{~min}$ after photoirradiation for $10 \mathrm{~min}$.

\section{Assumed structure of the trans-keto form}

When single crystals of I and II were irradiated with visible light, the unit-cell volumes increased by 29.7(2) and 15.3(2) $\AA^{3}$ at $173 \mathrm{~K}$, respectively. In contrast, the unit-cell volume of III decreased by 6.4(2) $\AA^{3}$ at $173 \mathrm{~K}$. Because the lifetime of colored species strongly depends on the void space in the crystal, it should follow the volume change of the unit cell. However, the unit-cell volume of III decreased after 2-1 isomerization, but the lifetime greatly decreased. Therefore, the change of the unit-cell volume has no correlation with the lifetime.

The above results may indicate that intermolecular interactions around the reactive site are the most important factor for the lifetime of the colored species. The structure of the colored species of $\mathrm{N}$-3,5-di-tert-butylsalicylideneaniline was successfully analyzed using two-photon excitation. The original cis-enol form transformed to the trans-keto form, as shown in Fig. 12(a). It has been proposed that this transformation should occur through pedal motion of the salicylideneaniline moiety around the central N1-C7 bond. ${ }^{22}$ The C4 and C10 atoms occupy nearly the same positions in pedal motion as shown in Fig. 12(b). This means that the void space around the central $-\mathrm{N} 1(\mathrm{H})-\mathrm{C}(\mathrm{H})$ - group should play

Table 3 Lifetimes of the trans-keto forms of I, II and III before and after visible-light irradiation

\begin{tabular}{|c|c|c|c|c|c|}
\hline \multicolumn{2}{|l|}{ I } & \multicolumn{2}{|l|}{ II } & \multicolumn{2}{|l|}{ III } \\
\hline $\begin{array}{l}\text { Irradiation } \\
\text { time/min }\end{array}$ & $\begin{array}{l}\text { Life } \\
\text { time/min }\end{array}$ & $\begin{array}{l}\text { Irradiation } \\
\text { time/min }\end{array}$ & $\begin{array}{l}\text { Life } \\
\text { time/min }\end{array}$ & $\begin{array}{l}\text { Irradiation } \\
\text { time/min }\end{array}$ & $\begin{array}{l}\text { Life } \\
\text { time/min }\end{array}$ \\
\hline 0 & 96 & 0 & 10 & 0 & 143 \\
\hline 4 & 45 & 20 & 20 & 5 & 47 \\
\hline 15 & 28 & 35 & 49 & 10 & 26 \\
\hline
\end{tabular}




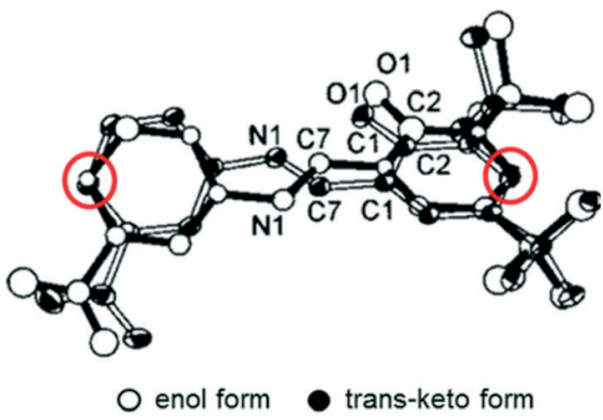

(a)

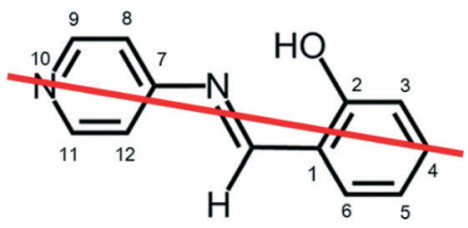

(b)

Fig. 12 (a) Observed structure of the trans-keto form of $\mathrm{SA}^{6}{ }^{6}$ and (b) the model structure of the trans-keto form of SAP, assuming that the pedal motion occurs keeping the carbon atom 4 and the nitrogen atom 10 in the same positions.

an important role in the cis-enol to trans-keto reaction and its back reaction.

\section{Size and shape of the cavity of the trans-keto form}

To estimate the void spaces around the active sites, the volumes of the cavities around the central $-\mathrm{N} 1(\mathrm{H})-\mathrm{C} 7(\mathrm{H})-$ groups of the trans-keto forms of I, I', II, II', III, and III' were calculated, assuming that the produced trans-keto form has the same relative position as the cis-enol form observed in each structure. The volumes of the cavities for the trans-keto forms of $\mathbf{I}$ and $\mathbf{I}^{\prime}$ are calculated in the same way as those proposed previously ${ }^{11}$ and the similar figures of the cavities are drawn in the previous paper. ${ }^{17}$ The cavity volumes are 4.1 and $4.5 \AA^{3}$ for I and $I^{\prime}$, respectively. The increase in the cavity volume after irradiation suggests a shorter lifetime after 2-1 isomerization than before isomerization, which is consistent with the observed lifetime of $\mathbf{I}$.

For the crystal structures of II and $\mathbf{I I}^{\prime}$, the cavities around the $-\mathrm{N} 1(\mathrm{H})-\mathrm{C} 7(\mathrm{H})-$ groups of the assumed trans-keto forms were calculated. Because the SAP moieties are disordered in II and II', only the major conformation was taken into account. However, similar results were obtained for the minor conformation. The cavity volumes of II and II' were calculated to be 2.5 and $2.2 \AA^{3}$, respectively. These values explain why the lifetime of II' (49 min after UV irradiation for $35 \mathrm{~min}$ ) is significantly longer than that of II (10 min).

\section{Conformation effect}

For the crystal structures of III and III', the cavities around the $-\mathrm{N} 1(\mathrm{H})-\mathrm{C} 7(\mathrm{H})-$ groups of the assumed trans-keto forms were calculated. The 2-cyanoethyl group in III transformed to the 1-cyanoethyl group with $R$ and $S$ configurations in III', and the $R / S$ ratio is $29: 20$. The cavity volume for the assumed trans-keto form of III is $3.0 \AA^{3}$. The corresponding cavity volumes of III' are 2.5 and $2.6 \AA^{3}$ for the $R$ and $S$ configurations, respectively. This suggests that the lifetime of the trans-keto form of III' should be longer than that of III. However, the lifetimes observed in the experiment were $143 \mathrm{~min}$ before irradiation and $26 \mathrm{~min}$ after $2-1$ isomerization, respectively.

The above results indicate that another factor should be taken into account. In the crystal structure of III, there are no effective intermolecular hydrogen bonds. The parallel conformation of the 2-cyanoethyl group may have some influence on the rate of the back reaction. Further experiments should be necessary for the parallel conformation.

\section{Structure of photochromic SAP}

It should be clarified why crystals of IV and V show no photochromism. It has been proposed that salicylideneaniline shows no photochromism if the dihedral angle between the salicylidene and aniline planes is less than $20^{\circ}$. If the dihedral angle is greater than $30^{\circ}$, it shows photochromism. If the dihedral angle is between $20^{\circ}$ and $30^{\circ}$, it depends on the crystal structure. $^{23}$ The molecular structures of IV and $\mathbf{V}$ are shown in Fig. 13(a) and (b), respectively. The dihedral angles between the planes of the salicylidene moiety and the 3-aminopyridine group are $21.8(4)^{\circ}$ and $18.1(3)^{\circ}$ for IV and V, respectively. These values indicate that crystals of IV and $\mathbf{V}$ show no photochromism. Conversely, the corresponding dihedral angles of I, II, and III are $47.8(2)^{\circ}, 88.6(5)^{\circ}$ (major part) and $77.1(11)^{\circ}$ (minor part), and $35.90(12)^{\circ}$, respectively. This is a reason why crystals of I, II, and III are photochromic, whereas crystals of IV and V are non-photochromic. It must be emphasized that although each SAP moiety in the former crystals is coordinated to the cobalt atom of the bulky cobaloxime moiety, it shows a

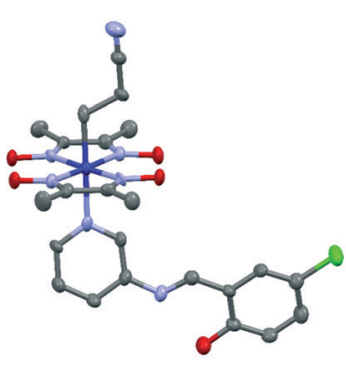

(a)

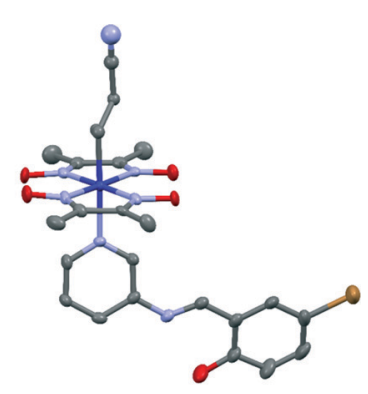

(b)
Fig. 13 Molecular structures of IV (a) and V (b). Hydrogen atoms are omitted for clarity. The thermal ellipsoids of atoms are drawn at the $50 \%$ probability level. The minor part of the 2 -cyanoethyl group of $\mathrm{V}$ is omitted for clarity. 
considerably large dihedral angle and therefore the photochromic behavior is conserved.

This work was partly supported by a Grant-in-Aid for Scientific Research in Priority Areas "New Frontiers in Photochromism (no. 471)" given to A. S. by the Ministry of Education, Culture, Sports, Science and Technology (MEXT), Japan. We thank Mr. Yuta Yamazaki for his useful assistance.

\section{References}

1 H. Dürr and H. Bouas-Laurent, Photochromism: Molecules and Systems, Elsevier, Amsterdam, 2003.

2 J. C. Crano and R. J. Guglielmetti, Organic Photochromic and Thermochromic Compounds, vol. 1 and 2, Plenum Press, 1999.

3 M. Irie, Chem. Rev., 2000, 100, 1685-1716.

4 M. Irie, Bull. Chem. Soc. Jpn., 2008, 81, 917-926.

5 A. Senier and F. G. J. Shepheard, J. Chem. Soc., Trans., 1909, 95, 1943-1955.

6 J. Harada, H. Uekusa and Y. Ohashi, J. Am. Chem. Soc., 1999, 121, 5809-5810.

7 M. Mikami and S. Nakamura, Phys. Rev. B: Condens. Matter Mater. Phys., 2004, 69, 134205.

8 K. Johmoto, A. Sekine, H. Uekusa and Y. Ohashi, Bull. Chem. Soc. Jpn., 2009, 82, 50-57.

9 J. Han, M. Maekawa, Y. Suenaga, H. Ebisu, A. Nabei, T. Kuroda-Sowa and M. Munakata, Inorg. Chem., 2007, 46, 3313-3321.

10 Y. Ohashi and Y. Sasada, Nature, 1977, 267, 142-144.
11 Y. Ohashi, K. Yanagi, T. Kurihara, Y. Sasada and Y. Ohgo, J. Am. Chem. Soc., 1981, 103, 5805-5812.

12 Y. Ohashi, Acc. Chem. Res., 1998, 21, 268-274.

13 A. Sekine, H. Tatsuki and Y. Ohashi, J. Organomet. Chem., 1997, 536-537, 389-398.

14 A. Sekine and Y. Ohashi, Bull. Chem. Soc. Jpn., 1991, 64, 2183-2187.

15 A. Sekine, H. Yamagiwa and H. Uekusa, Chem. Lett., 2012, 41, 795-797.

16 H. Yamagiwa and A. Sekine, Bull. Chem. Soc. Jpn., 2013, 86, 1028-1034.

17 Y. Yamazaki, A. Sekine and H. Uekusa, Cryst. Growth Des., submitted.

18 G. M. Sheldrick, Acta Crystallogr., Sect. A: Found. Crystallogr., 2008, 64, 112-122.

19 M. C. Burla, R. Caliandro, M. Camalli, B. Carrozzini, G. L. Cascarano, C. Giacovazzo, M. Mallamo, A. Mazzone, G. Polidori and R. Spagna, J. Appl. Crystallogr., 2012, 45, 357-361.

20 G. M. Sheldrick, Acta Crystallogr., Sect. A: Found. Adv., 2015, 71, 3-8.

21 G. R. Desiraju and T. Steiner, The Weak Hydrogen Bond in Structural Chemistry and Biology, Oxford University Press, New York, 1999.

22 K. Ogawa, T. Sano, S. Yoshimura, Y. Takeuchi and K. Toriumi, J. Am. Chem. Soc., 1992, 114, 1041-1051.

23 K. Johmoto, T. Ishida, A. Sekine, H. Uekusa and Y. Ohashi, Acta Crystallogr., Sect. B: Struct. Sci., Cryst. Eng. Mater., 2012, 68, 297-304. 